\title{
Predication of Pavement Performance for Highway Sections with Special Geometric Features
}

\author{
Hassan Salama* \\ Associate professor \\ Nasser Gonah* \\ Ph. D. Candidate \\ Mahmoud Solyman** \\ Assistant professor \\ Mohamed El Refaey* \\ Assistant professor \\ ${ }^{*}$ Civil \& Environmental Engineering Department, Al Azhar University, Egypt \\ ${ }^{* *}$ Construction Engineering Department, Zagazig University, Egypt
}

\begin{abstract}
The current state-of-the-practice for pavement design only accounts for traffic load application without considering the speed and highway geometry as design criterion. This paper investigates the effect of geometric design elements including horizontal curves, vertical gradients and U-turns on pavement performance at different traffic characteristics and pavement structures. The effects of theses parameters on Pavement Condition Index (PCI) and International Roughness Index (IRI) were investigated using simple, multiple, and stepwise linear regression to develop prediction models for special geometric sections. In this study, field data were collected for surface pavement distresses, for sections with special geometric features, varied traffic characteristics, and different pavement structures. Comparison between the pavement conditions of sections with special geometric features and those of their reference straight road sections was performed. The results showed significant difference between PCI of special geometric sections and their reference sections. So, the geometry factor needs to be considered in structural design of pavements. This paper also showed that speed is one of the most important factors influencing pavement deterioration especially at upgrade sections and horizontal curves. Prediction models were built to forecast the pavement conditions for sections with vertical gradients and horizontal curves.
\end{abstract}

Keywords: Special Geometric Sections, Pavement Conditions, International Roughness Index,

Regression Analysis

\section{Background}

Pavement performance is a function of several factors some of which are not constant along the road. Hence, the deterioration rate varies in the longitudinal direction of the road, where some sections experience more deterioration than others. The pavement deterioration could accelerate at the roads sections that have special geometry such as horizontal curves and vertical gradient, intersections, Uturns, and stopping areas along with the remarkable increase in the allowable maximum loads and tire pressure or significant decrease in the speed at these locations.

The current state-of-the-practice for pavement design applies the same pavement layer thickness, materials, and specification to the entire road without taking into account the geometric properties of the road. Hence, some sections suffer from premature deterioration more than others within the same road. Very few researchers have investigated the influence of the geometric features and traffic characteristics on pavement performance. This paper develops a regression models to predict the pavement performance at road segments with special geometric features.

Kandhal, et. al. 1998 and Hajj, et al, 2007investigated the presence of pavement distresses at the 
special geometric sections such as intersections, they found that there is no significant rutting and shoving in the same road away from the intersection due to the difference in the rate of loading at the intersections. Abd El Halim et al., 1996 investigated the effect of highway geometry on the surface cracking of asphalt pavement. Their investigations showed that the geometry of a highway plays a major role in the occurrence of the surface cracking. The results indicated that the number of pavement transverse cracks in both Egyptian and Canadian highway networks were significantly higher on the horizontal curve sections than those on the straight sections. Gillespie and his group at UMTRI, 1993 investigated the forces that cause pavement distresses at special geometric sections. They found that accelerating, braking and cornering maneuvers place additional stress on a pavement surface. In accelerating and braking maneuvers the weight of the vehicle shifts longitudinally, whereas the cornering maneuvers shifts the axle weight laterally. Thus, the maneuvers change wheel loads affecting the normal stresses on the pavement. The tire traction and cornering forces which are necessary to accomplish the maneuvers impose additional shear stresses on the pavement surface. These unaccounted loadings accelerate pavement damage at these locations. Chang, 2001 studied the unaccounted loading in the pavement design at the special geometric sections especially at horizontal curves. His study showed that when a vehicle travels on a horizontal curve a portion of the vehicle weight is shifted to the outside tires resulting in excessive lateral forces. In some cases, the load on the inside wheels reaches zero and lifts off the ground and the load in the outside tires is increased by double the magnitude of the designed load. Usually, the pavement at the horizontal curve sections are not designed to carry excessive loads due to unequal axle loads resulting from lateral shifting of the vehicles weight.

The pavement responses variations (stress, strain and deflection) have a great impact on pavement performance as these responses directly affect the type and severity of pavement distresses. These pavement responses are affected by several major factors that, in general, are related to the vehicle, tire, pavement and environmental conditions. Christison et al, 1978, Chatti et al, 1996, Mikhail and Mamlouk, 1997, investigated the effect of vehicle speed on asphalt pavement strains in the field. Results from these studies showed that the total strain in pavement decreased as the vehicle speed increased. Pereira et al, 1999, found that the effect of truck speed on the accumulation of permanent deformation needs to be considered. They noted that some of the highway sections exhibited increase rutting as the truck speed decreased. In general, it can be concluded that speed reduction will increase the pavement response, subsequently the damage of pavements increased. So, the influence of speed variation affects the severity of pavement distresses along the roads.

This paper investigates the effect of highway geometry and traffic characteristics on flexible pavement damage from in-service pavement distress data through building a regression models to predict the pavement condition index from factors influencing these conditions. Field surveys for 115 pavement sections with special geometric features and the adjacent straight sections (reference sections) were conducted. Statistical analysis was carried out to compare between pavement distresses at both special sections and their references. The effects of theses parameters on Pavement Condition Index (PCI) and International Roughness Index (IRI) were investigated using simple, multiple, and stepwise linear regression. Also, sensitivity analysis of the significant parameters was conducted to compare between these parameters and their effects on pavement conditions.

\section{Data Collection}

The field survey includes the following:

1. Pavement Conditions

2. Geometric Features

3. Traffic Characteristics

4. Pavement Structure

This field data was gathered to establish the relation between pavement conditions and special geometric locations at different traffic characteristics. The traffic characteristics include cumulative traffic load (CESALs), traffic speed and Annual Average Daily Truck Traffic (AADTT). The 
pavement structure includes pavement layer thickness and materials used to calculate the Structure Number (SN). Pavement distresses and roughness were collected for 115 sections that have horizontal curves, vertical gradient or U-turns. To study the effect of these geometric features on pavement damage, each of the previous sections that have special geometry were compared with the adjacent straight section (its reference section). These sections are located over the following four main roads on the Egyptian road network:

- Cairo - Alexandria Agricultural Highway (CAA) - 43 sections

- Tanta - Damietta Agricultural Highway (TDA) - 50 sections

- Cairo - Alexandria Desert Highway (CAD) - 8 sections

- Cairo - Ismailia Desert Highway (CID) - 14 sections

The selected sections have flexible pavement type, variation in traffic characteristics and pavement conditions. Figure 1 shows the roads included in the study.

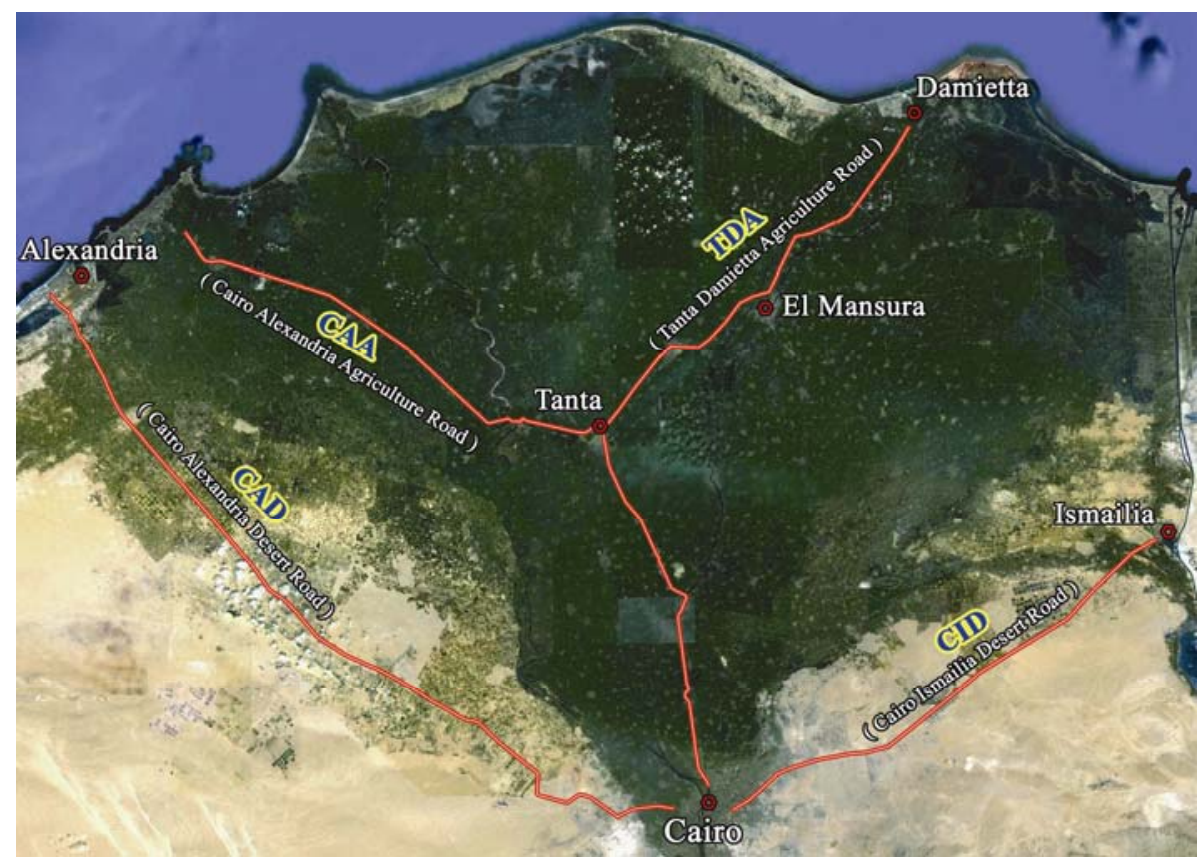

Figure 1: Map of roads included in the study

\subsection{Features of Selected sections}

Each selected section has the following criteria:

1. Located on a main highway in Egypt.

2. Have the same number of lanes throughout the entire length of section,

3. Constructed at the same time by the same contractor,

4. Have a uniform asphalt mixes and same thickness and material of the entire wearing, base, subbase, and subgrade layers,

5. Have the same length which is $100 \mathrm{~m}$,

After selection of the sections, relevant information was collected from the regional highway agency for each road. Sections which failed to meet the above selected criterion were excluded from the analysis. Preliminary site visits were made to each of the selected sections to compare the data collected from the agency and the road maps to the actual field conditions. Table 1 shows all variables considered in the analysis and Table 2 shows the total number of sections for each alignment type, more details description of road sections and data collections can be found in Gonah, 2009. 
Table 1: All variable related this study

\begin{tabular}{|c|c|c|c|}
\hline $\begin{array}{l}\text { Pavement Condition } \\
\text { Variable }^{*}\end{array}$ & Traffic Variable ${ }^{* *}$ & $\begin{array}{l}\text { Geometric } \\
\text { Variable** }\end{array}$ & $\begin{array}{l}\text { Pavement } \\
\text { Variable }^{* *}\end{array}$ \\
\hline $\begin{array}{l}\text { - Pavement Condition } \\
\text { Index (PCI) } \\
\text { - International } \\
\text { Roughness Index } \\
\text { (IRI) }\end{array}$ & $\begin{array}{l}\text { - Traffic Volume AADT } \\
\text { - Passenger Car Speed }(\mathrm{km} / \mathrm{h}) \\
\text { - Truck Speed }(\mathrm{km} / \mathrm{h}) \\
\text { - ESALs } / \text { Lane } / Y \text { ear }\left(10^{6}\right) \\
\text { - Truck Percent T\% } \\
\text { - AADTT } \\
\text { - CESALs } / \text { Lane }\left(10^{6}\right) \\
\text { - Average speed }(\mathrm{km} / \mathrm{h})\end{array}$ & $\begin{array}{l}\text { - Radius ( m) } \\
\text { - Superelevation e\% } \\
\text { - Grade \% } \\
\text { - Lane Width (m) } \\
\text { - No. of Lanes }\end{array}$ & $\begin{array}{l}\text { - Structure } \\
\text { Number SN } \\
\text { - Age (year) }\end{array}$ \\
\hline
\end{tabular}

Table 2: Number of sections according to alignment types

\begin{tabular}{|l|l|c|}
\hline Road Name & Alignment Type & No. of Sections \\
\hline \multirow{2}{*}{ Cairo-Alexandria Agricultural (CAA) } & Vertical grade & 20 \\
\cline { 2 - 3 } & Horizontal curve & 23 \\
\hline \multirow{2}{*}{ Tanta-Damietta Agricultural (TDA) } & Vertical grade & 2 \\
\cline { 2 - 3 } & Horizontal curve & 48 \\
\hline \multirow{3}{*}{ Cairo-Alexandria Desert (CAD) } & Vertical grade & 4 \\
\cline { 2 - 3 } & Horizontal curve & 2 \\
\cline { 2 - 3 } & U-turn & 2 \\
\hline \multirow{2}{*}{ Cairo-Ismailia Desert (CID) } & Vertical grade & 4 \\
\cline { 2 - 3 } & Horizontal curve & 5 \\
\cline { 2 - 3 } & U-turn & 5 \\
\hline
\end{tabular}

\subsection{Pavement Condition Evaluation Method}

Two performance measures were taken into consideration to evaluate the pavement condition:

1- Pavement surface distresses were collected through visual inspection according to SHRP distress identification manual. The Pavement Condition Index (PCI) for each section was calculated using MicroPAVER software. In this technique, the pavement condition is characterized based on a numerical rating from 0 to 100 where 0 indicates very poor pavement condition whereas 100 indicate excellent pavement condition. There are three pavement distress characteristics that have significant effect upon the determination of the degree of deterioration and hence the PCI:

- Type of distress,

- Severity of distress, and

- Amount or density of distress.

The distress survey includes only the outside (slow) lane where most trucks travel causing more distress.

2- International Roughness index which measures pavement roughness in terms of the number of inches $/$ mile $(\mathrm{m} / \mathrm{km})$ that a laser, mounted in a specialized van, jumps as it is driven across the highway. The lower the IRI number, the smoother the ride along the road. The surface roughness is an important indicator of pavement condition assessment that is identified from the calculated IRI. The collected data along the road profile was processed by ROMDAS software package to calculate the IRI for each section.

Those two pavement performances (PCI and IRI) were used to evaluate the pavement condition for both types of pavement sections, sections with special geometric features and their reference sections. 


\section{Statistical Data Analysis}

Statistical analysis was employed to examine the difference in pavement performance data between pavement sections located at horizontal curves, vertical gradient, and U-turns with straight sections. Analysis of variance (ANOVA) was used to compare the means of PCI and IRI and to determine whether the difference is statistically significant for sections with special geometric features than those straight sections or not. Regression models were developed for sections with both special geometric features and straight sections where the numbers of sections support building a reliable regression models.

\subsection{Analysis of Variance for PCI and IRI}

The Analysis of Variance (ANOVA) was used to compare the performance means of the special geometric sections with their reference sections. One-way ANOVA was applied to investigate whether the performance means of PCI and IRI at special geometric sections and their references are significantly different from each other or not. This analysis was obtained using SPSS software for different geometric alignment types as follows:

- Horizontal curve sections

- Vertical gradient sections

- U-turn sections

The ANOVA results of PCI at special geometric sections and their references are summarized in Table 3. In addition, this table includes the descriptive statistics of the PCI data. As shown in the table, the mean of PCI at horizontal curve sections is significantly different from the mean of PCI at their reference sections $(p$-value $<0.05)$. The results showed also that the means of PCI at vertical gradient and U-turn sections are significantly different from the means of PCI at their reference sections $(p$-value $<0.05)$. These results indicate that road sections with special geometric features have higher surface pavement distresses than straight sections.

Table 3: ANOVA and Descriptive statistics of PCI at special geometric sections and their references

\begin{tabular}{|l|l|c|}
\hline \multicolumn{2}{|c|}{ One-way ANOVA } \\
\hline $\begin{array}{c}\text { Alignment } \\
\text { type }\end{array}$ & \multicolumn{1}{|c|}{ Item } & Main Effect \\
\hline \multirow{4}{*}{$\begin{array}{l}\text { Horizontal } \\
\text { Curve }\end{array}$} & Sum of Squares & 86151.28 \\
\cline { 2 - 3 } & Mean Square & 86151.28 \\
\cline { 2 - 3 } & $\mathrm{F}$ & 174.46 \\
\cline { 2 - 3 } Vertical & $p$-value & 0.00 \\
\hline \multirow{4}{*}{ grade } & Sum of Squares & 47185.71 \\
\cline { 2 - 3 } & Mean Square & 47185.71 \\
\cline { 2 - 3 } & $\mathrm{F}$ & 379.52 \\
\cline { 2 - 3 } & $p$-value & 0.000 \\
\hline \multirow{4}{*}{ U-turn } & Sum of Squares & 13084.57 \\
\cline { 2 - 3 } & Mean Square & 13084.57 \\
\cline { 2 - 3 } & $\mathrm{F}$ & 95.90 \\
\cline { 2 - 3 } & $p$-value & 0.00 \\
\hline
\end{tabular}

\begin{tabular}{|l|c|c|}
\hline \multicolumn{3}{|c|}{ Descriptive Statistics } \\
\hline Item & $\begin{array}{c}\text { PCI of } \\
\text { sections }\end{array}$ & $\begin{array}{c}\text { PCI of Reference } \\
\text { sections }\end{array}$ \\
\hline $\mathrm{N}$ & 73 & 73 \\
\hline Minimum & 1 & 50 \\
\hline Maximum & 100 & 100 \\
\hline Mean & 30.21 & 78.79 \\
\hline $\mathrm{N}$ & 30 & 30 \\
\hline Minimum & 5 & 41 \\
\hline Maximum & 62 & 94 \\
\hline Mean & 17.34 & 73.43 \\
\hline $\mathrm{N}$ & 7 & 7 \\
\hline Minimum & 3 & 55 \\
\hline Maximum & 31 & 91 \\
\hline Mean & 14.57 & 75.71 \\
\hline
\end{tabular}


Similarly, one-way ANOVA was applied to the IRI data for all geometric alignment types and their references sections. Table 4 shows the ANOVA results and descriptive statistics of IRI for all geometric alignment types. The results indicate that the mean of IRI at horizontal and vertical gradient sections are significantly different from the mean of IRI of their reference sections $(p$-value $<0.05)$. These results indicate that pavement sections with special geometric sections are more rougher than straight sections.

Table 4: ANOVA and Descriptive Statistics of IRI at special geometric sections and their references

\begin{tabular}{|l|l|c|}
\hline \multicolumn{3}{|c|}{ One-way ANOVA } \\
\hline $\begin{array}{c}\text { Alignment } \\
\text { type }\end{array}$ & \multicolumn{1}{|c|}{ Item } & Main Effect \\
\hline \multirow{4}{*}{$\begin{array}{l}\text { Horizontal } \\
\text { curve }\end{array}$} & Sum of Squares & 90.69 \\
\cline { 2 - 3 } & Mean Square & 90.69 \\
\cline { 2 - 3 } & $\mathrm{F}$ & 9.911 \\
\cline { 2 - 3 } & p-value & 0.04 \\
\hline \multirow{4}{*}{$\begin{array}{l}\text { Vertical } \\
\text { grade }\end{array}$} & Sum of Squares & 72.29 \\
\cline { 2 - 3 } & Mean Square & 72.29 \\
\cline { 2 - 3 } & $\mathrm{F}$ & 4.89 \\
\cline { 2 - 3 } & $p$-value & 0.04 \\
\hline
\end{tabular}

\begin{tabular}{|l|c|c|}
\hline \multicolumn{3}{|c|}{ Descriptive Statistics } \\
\hline Item & $\begin{array}{c}\text { IRI of } \\
\text { sections }\end{array}$ & $\begin{array}{c}\text { IRI of Reference } \\
\text { sections }\end{array}$ \\
\hline $\mathrm{N}$ & 17 & 17 \\
\hline Minimum & 1.8 & 1.1 \\
\hline Maximum & 19.5 & 4.36 \\
\hline Mean & 5.88 & 2.6 \\
\hline $\mathrm{N}$ & 8 & 8 \\
\hline Minimum & 3.7 & 1.3 \\
\hline Maximum & 19.81 & 4.38 \\
\hline Mean & 6.58 & 2.33 \\
\hline
\end{tabular}

After demonstrating that pavement sections with special geometric features have more surface pavement distresses and are rougher than straight pavement sections, alignment types with more pavement sections (more than 25) were utilized to build a regression models.

\subsection{Regression Analysis}

The collected data were used to investigate the relationships between pavement conditions as dependent variables and geometric design features, pavement structure and traffic characteristics as independent variables at special geometric sections along the roads. Univariate linear regression for PCI and IRI were used to check the correlation coefficient between these two dependent variables and all independent variables, see Table 1 . However no sufficient field data for IRI were available to build a regression model with higher correlation coefficients. The independent variables that have relatively high correlation coefficient $\left(\mathrm{R}^{2}\right)$ values with the PCI were introduced into the multiple linear regression models. Among several dependent variables introduced to the multiple linear regression models, stepwise regression analysis was used to select the most statistically significant variables. These variables include: 1) traffic speed, 2) Cumulative Equivalent Single Axle Loads, CESALs, 3) Radius of horizontal curves, R, 4) Longitudinal grade, 5) Structure number (SN) and 6) Pavement age.

\subsubsection{Model Precautions}

Several precautions were taken into consideration to ensure integrity of the model as follows (Neter, Wasserman, 1974):

- The signs of the multiple linear regression coefficients should agree with the signs of the simple linear regression of the individual independent variables,

- The signs of the multiple linear regressions for each independent variable should agree with intuitive engineering judgment. For example, higher CESALs should decrease the PCI.

- There should be no multicollinearity among the final selected independent variables. For example, two independent variables having the same effect (high univariate correlation) on the dependent variable should not be included in one model at the same time. 
- One of several variable selection algorithms (e.g. stepwise, forward, and backward regression analyses) was used in regression to eliminate the statistically insignificant independent variables for each of the models.

- The model with the smallest number of independent variables, minimum standard error, and highest $\mathrm{R}^{2}$ value was selected.

\subsubsection{Horizontal Curve Sections}

A total of 78 horizontal curve sections were used for predicting PCI at horizontal curve alignment. All available data related to horizontal alignment, traffic characteristics, and pavement structure were regressed with the PCI. The dependant variables that have good correlation (higher $\mathrm{R}^{2}$ ) with the PCI were introduced to the multiple linear regression. Stepwise regression was used to select the most statistically significant independent variables, Equation 1 shows the final regression Equation. The final number of sections after excluding the outliers through Cook's distance becomes 56 sections.

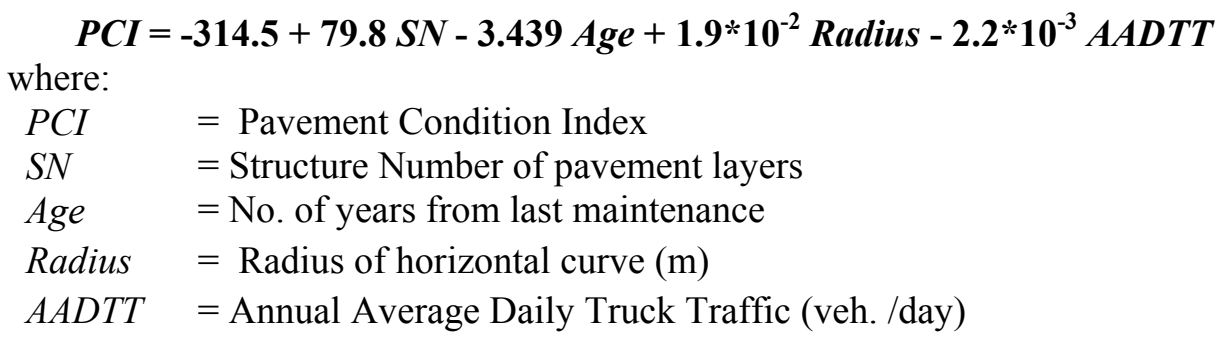

Table 4 shows that the overall model of PCI for horizontal curve sections is statistically significant and the $\mathrm{R}^{2}$ of the model is 0.747 which means that the PCI showed relatively high correlation with the final selection of independent variables listed in Equation 1.

To ensure reliability of the regression equation and no violation of the regression assumption, the normality of all variables included in Equation 1 were checked and the cook's distance was used to exclude the outliers from the data. Also, there was no concern about the multicollinearity (VIF $<10$ ) as shown in Table 5. Moreover, there is an agreement between the multiple linear regression coefficient signs and the univariate relationship of the individual variables (for more details see Gonah, 2009). The regression model shows that:

- The higher the structural number and /or the horizontal curve radius, the higher the PCI, which means a lower rate of deterioration of pavement with thicker pavement layers. Also, horizontal curve with small radius will show more distresses than larger curve one.

- The higher the traffic volume (AADTT) the lower is PCI, which means a higher rate of pavement deterioration with increase of traffic volume including more truck percentage.

- Also, pavement deteriorates more with time, which means that pavement with lower PCI will show more distress over a longer period of time (longer age).

\subsubsection{Vertical gradient Sections}

A total of 30 sections were used for predicting PCI for vertical curve sections. Similar procedures were used to finalize the vertical curve model. Equation 2 shows the final regression equation after running the multiple linear regression and stepwise regression to select the final independent variables. The final number of sections after excluding the outliers through Cook's distance becomes 29 sections.

$$
P C I=22.42+0.27 V-7.71 * 10^{-2} \text { CESALs }-4.26 G
$$

Where:

$\begin{array}{ll}P C I & =\text { Pavement Condition Index } \\ V & =\text { Average speed }(\mathrm{km} / \mathrm{h}\end{array}$ 


$$
\begin{array}{ll}
\text { CESALs } & =\text { Cumulative Equivalent Singe Axle Loads } \\
G & =\text { Grade }(\%) \text { as a value without sign }
\end{array}
$$

Table 4 shows that the overall model of PCI for vertical curve sections is statistically significant and the overall $\mathrm{R}^{2}$ equals 0.624 which means that the PCI showed high correlation with independent variables listed in the Equation 2. As mentioned, the normality of all variables included in Equation 2 was checked along with the cook's distance and multicollinearity (VIF $<10)$ as shown in Table 5. The regression model shows that:

- The higher the traffic speed, the higher the PCI, which means a lower rate of deterioration of pavement with high speed of road sections.

- The higher the traffic volume and repetition (CESALs) of heavy traffic, the lower the PCI, which means a higher rate of pavement deterioration with increasing of ESAL.

- Higher rate of pavement deterioration occurs in higher longitudinal grade due to speed reduction especially for heavy trucks.

\subsubsection{Straight Sections}

A total of 46 straight sections (reference sections) were used for predicting PCI for straight alignment. Equation 3 shows the final regression equation after running the multiple linear regression and stepwise regression to select the final independent variables. The final number of sections after excluding the outliers through Cook's distance becomes 45 sections.

$$
P C I=-305.32+1.21 \mathrm{~V}+71.99 \mathrm{SN}-\mathbf{5 . 0 4 5} \text { Age }
$$

where:

$$
\begin{array}{ll}
P C I & =\text { Pavement Condition Index } \\
V & =\text { Average speed }(\mathrm{km} / \mathrm{hr}) \\
S N & =\text { Structure number } \\
\text { Age } & =\text { No. of years from last maintenance }
\end{array}
$$

Table 4 shows that the overall model of PCI for straight sections is statistically significant and the overall $\mathrm{R}^{2}$ equals 0.681 which means that the PCI showed high correlation with independent variables listed in Equation 3. As mentioned, the normality of all variables included in Equation 3 was checked along with cook's distance and multicollinearity (VIF $<10)$ see Table 5.

The standardized regression coefficient shows that:

- The higher the speed of traffic, the higher the PCI. In other words, speed reduction at special geometric sections increase the pavement response (horizontal and vertical compressive strains) which causes rapid pavement deterioration at these sections.

- The higher the structural number, the higher the PCI. In other words, pavement with lower structure integrity deteriorates faster and vice versa.

- Also, pavement deteriorates more with time, which means that PCI decrease with time.

Table 4: Model summary for PCI of Horizontal curve, vertical curve and straight sections

\begin{tabular}{|l|c|c|c|c|c|c|c|}
\hline & \multirow{2}{*}{ Alignment type $^{\mathrm{a}}$} & \multirow{2}{*}{$\mathrm{R}$} & \multirow{2}{*}{$\mathrm{R}^{2}$} & \multirow{2}{*}{ Adjusted $\mathrm{R}^{2}$} & \multirow{2}{*}{$\begin{array}{c}\text { Std. error of } \\
\text { the estimate }\end{array}$} & \multicolumn{3}{|c|}{ change statistics } \\
\cline { 6 - 9 } & & & & $\mathrm{R}^{2}$ change & F Change & $P$-value \\
\hline Horizontal curve & $0.864^{\mathrm{b}}$ & 0.747 & 0.717 & 15.97 & 0.021 & 4.24 & 0.045 \\
\hline Vertical curve & $0.790^{\mathrm{c}}$ & 0.624 & 0.579 & 7.0411 & 0.103 & 6.851 & 0.015 \\
\hline Straight & $0.816^{\mathrm{d}}$ & 0.681 & 0.657 & 19.4073 & 0.070 & 8.927 & 0.005 \\
\hline
\end{tabular}

\footnotetext{
${ }^{\mathrm{a}}$ Dependent variable PCI

${ }^{\mathrm{c}}$ Predictors (constant), Average speed, CESALs, Grade

${ }^{\mathrm{b}}$ Predictors (constant), SN, Age, Radius, AADTT

${ }^{\mathrm{d}}$ Predictors (constant), Average speed, SN, Age
} 
Table 5: Model coefficient for PCI at curved sections

\begin{tabular}{|c|c|c|c|c|c|c|c|c|}
\hline \multirow{2}{*}{$\begin{array}{l}\text { Alignment } \\
\text { type }\end{array}$} & \multirow{2}{*}{ Variable } & \multicolumn{2}{|c|}{$\begin{array}{c}\text { Unstandardized } \\
\text { Coefficients }\end{array}$} & \multirow{2}{*}{$\begin{array}{c}\text { Standardized } \\
\text { Coefficients } \\
\text { Beta (Rank) }\end{array}$} & \multirow{2}{*}{$\mathrm{t}$} & \multirow{2}{*}{ Seg. } & \multicolumn{2}{|c|}{$\begin{array}{c}\text { Collinearity } \\
\text { Statistics }\end{array}$} \\
\hline & & Beta & $\begin{array}{l}\text { Std. } \\
\text { Error }\end{array}$ & & & & Tolerance & VIF $^{*}$ \\
\hline \multirow{5}{*}{$\begin{array}{l}\text { Horizontal } \\
\text { curve }\end{array}$} & Constant & -314.55 & 35.78 & & -8.79 & 0.000 & & \\
\hline & SN & 79.79 & 7.41 & 0.788 (1) & 10.75 & 0.000 & 0.92 & 1.08 \\
\hline & Age & -3.44 & 0.56 & $-0.432(2)$ & -6.09 & 0.000 & 0.98 & 1.01 \\
\hline & Radius & $1.9 \mathrm{E}-02$ & 0.007 & $0.22 \quad$ (3) & 2.96 & 0.000 & 0.89 & 1.11 \\
\hline & AADTT & $-2.2 * 10^{-3}$ & 0.001 & $-0.148(4)$ & -2.06 & 0.05 & 0.95 & 1.05 \\
\hline \multirow{4}{*}{$\begin{array}{l}\text { Vertical } \\
\text { grade }\end{array}$} & Constant & 22.41 & 8.76 & & 2.55 & 0.017 & & 1.00 \\
\hline & CESALs & $-7.7 \mathrm{E}-02$ & 0.018 & $-0.517(\mathbf{1})$ & -4.19 & 0.000 & 0.99 & 1.01 \\
\hline & Average speed & 0.27 & 0.091 & $0.396(2)$ & 2.95 & 0.007 & 0.83 & 1.00 \\
\hline & Grade & -4.26 & 1.629 & $-0.35(3)$ & -2.61 & 0.015 & 0.82 & 1.21 \\
\hline \multirow{4}{*}{ Straight } & Constant & -305.32 & 54.27 & & -5.62 & 0.00 & & \\
\hline & Average speed & 1.211 & 0.18 & $0.63(1)$ & 6.63 & 0.00 & 0.86 & 1.15 \\
\hline & SN & 71.9 & 13.56 & $0.58(2)$ & 5.31 & 0.00 & 0.63 & 1.57 \\
\hline & Age & -5.0 & 1.68 & $-0.34(3)$ & -2.98 & 0.005 & 0.60 & 1.65 \\
\hline
\end{tabular}

a. Dependent variable PCI $\quad{ }^{*}$ Variance Inflation Factor

Table 5 shows the standardized regression coefficients values which determined from converting all variables (dependent and independent) into Z-score. Having the variables in Z-score form will convert the distribution means to zero and standard deviation to one, such that all variables will have common measurement scale and one can determine which independent variable is relatively more important. Ranking the independent variables (as shown in Table 5) indicate that special care should be taken for the structure design at the horizontal curve locations due to excessive axle load resulting from lateral force. Cumulative heavy axle load with its speed represent the major cause of pavement deterioration at the vertical curve locations. For straight sections, traffic speed is a major player in causing pavement deterioration due to the relationship between the speed and pavement response.

Table 6 shows the descriptive statistics where the regression models should be used within the range of the variables to insure reliable prediction of the PCI.

Table 6: Descriptive statistics of dependent and independent variables

\begin{tabular}{|c|l|c|c|c|c|}
\hline Alignment type & \multicolumn{1}{|c|}{ Variables } & Minimum & Maximum & Mean & Std. Deviation \\
\hline \multirow{4}{*}{$\begin{array}{c}\text { Horizontal } \\
\text { curve }\end{array}$} & PCI & 2 & 100 & 34.17 & 30.57 \\
\cline { 2 - 6 } & Radius (m) & 103.3 & 2409.5 & 533.48 & 345.46 \\
\cline { 2 - 6 } & SN & 3.8 & 5.12 & 4.67 & 0.30 \\
\cline { 2 - 6 } & Age (year) & 0 & 14 & 8.107 & 3.84 \\
\cline { 2 - 6 } & AADTT(vehicle/day) & 80.12 & 6678.79 & 2929.83 & 2078.73 \\
\hline \multirow{5}{*}{\begin{tabular}{l} 
Vertical curve \\
\cline { 2 - 6 }
\end{tabular}} & PCI & 5.00 & 41.00 & 17.77 & 10.84 \\
\cline { 2 - 6 } & Grade (\%) & 0.63 & 4.95 & 3.04 & 0.89 \\
\cline { 2 - 6 } & $\begin{array}{l}\text { Average speed } \\
\text { (km/hr) }\end{array}$ & 24.25 & 80.92 & 55.51 & 16.0 \\
\cline { 2 - 6 } & CESALs (106) & 5.65 & 206.46 & 85.34 & 72.75 \\
\hline \multirow{5}{*}{\begin{tabular}{l} 
Straight \\
\cline { 2 - 6 }
\end{tabular}} & PCI & 4.00 & 98.00 & 61.00 & 33.14 \\
\cline { 2 - 6 } & SN & 3.80 & 5.12 & 4.53 & 0.27 \\
\cline { 2 - 6 } & Age(year) & 6.00 & 14.00 & 8.35 & 2.22 \\
\cline { 2 - 6 } & Average speed(km/hr) & 28.00 & 91.50 & 67.66 & 17.24 \\
\hline
\end{tabular}




\subsubsection{Models Validation}

One important step in building a regression models to insure integrity of the models is to check the prediction on independent variables other than the dataset that used in developing the model. 6 horizontal curve data, 8 vertical curve data, and 7 straight sections data other than the data used to develop the regression models were used to predict the PCI and compare the prediction valued with the actual values of PCI as shown in Figure 5. The figure shows a fair prediction of PCI and the correlation coefficients are $0.747,0.624$, and 0.683 for horizontal, vertical, and straight sections, respectively.

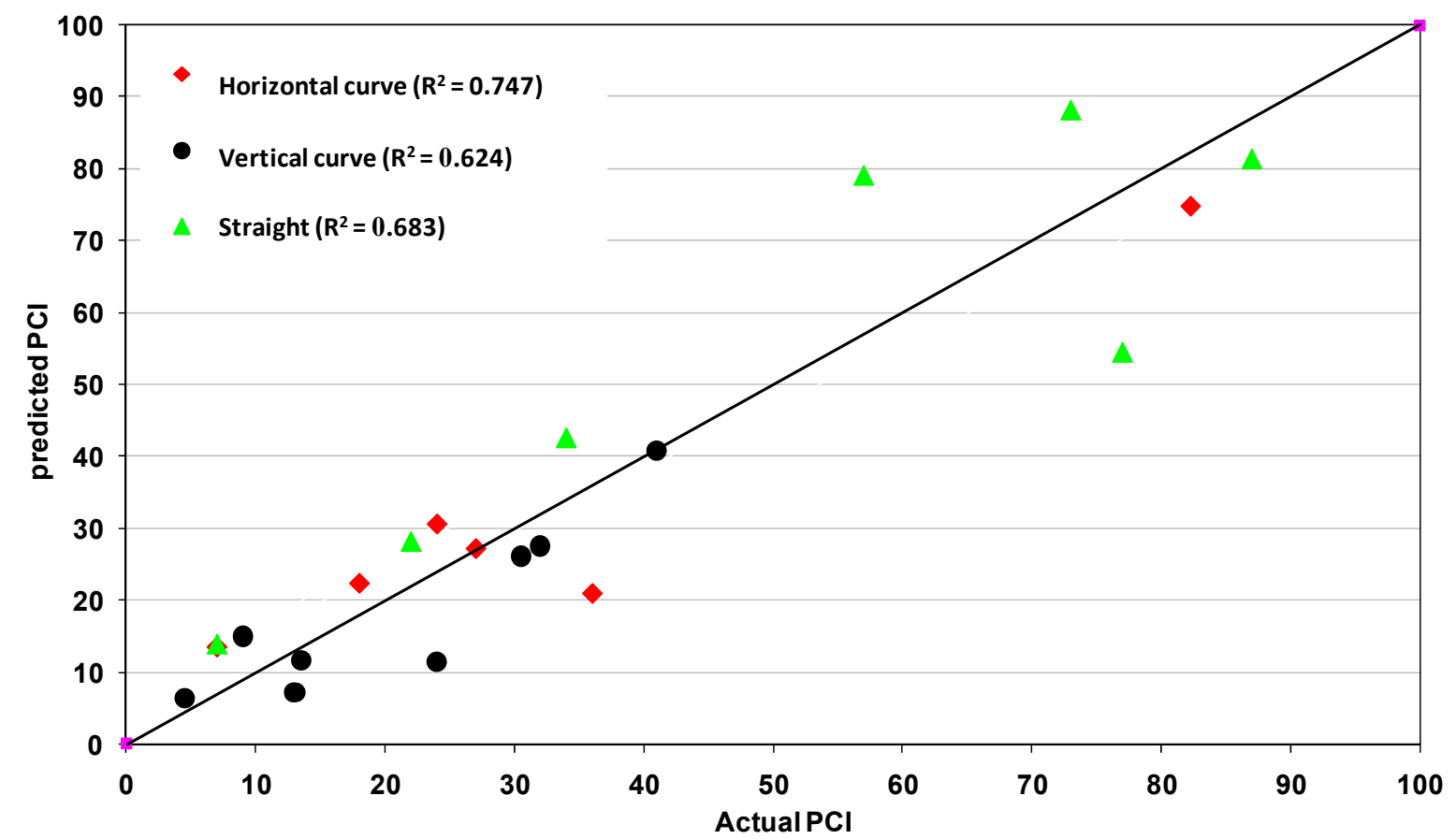

Figure 5: Actual versus Predicted values of PCI for all alignment types

\section{CONCLUSION}

Based on the investigation of the relationship between pavement conditions variables, traffic variables, geometric variables, and pavement variables, the following conclusions can be drawn:

- Significant difference between pavement surface distresses and pavement roughness at straight sections and sections with special geometric features such as horizontal and vertical curves as well as U-turns.

- Pavement Condition Index can be predicted at horizontal and vertical curve locations as well as at the straight sections through the developed regression models. Model precautions, model checks, and model validation were considered to insure reliable predictions.

- Horizontal curve model showed that special care should be taken for the structure design at the horizontal curve locations due to excessive axle load resulting from lateral force.

- Vertical curve model showed that cumulative heavy axle load with its speed represent the major cause of pavement deterioration at the vertical curve locations. 


\section{ACKNOWLEDGEMENT}

The Authors would like to thank Dr. Abdel Allah Wahdan, Vice Dean of Faculty of Engineering, Al Azhar University and former Director of National Institute of Transportation, Ministry of Transportation, Cairo, for his continuous support during this research.

\section{References}

Prithvi S. Kandhal, Rajib B. Mallick, Elton R. Brown, 1998. Hot Mix Asphalt for Intersections in Hot Climates, NCAT Report 98-06

E. Hajj, Sebaaly, P. E., Siddharthan, R., Weitzel, D. (2007), "Investigation \& Analysis of Hot Mix Asphalt Mixtures at Nevada's Intersections," International Conference on Advanced Characterization of Pavement and Soil Engineering Materials, Athens, Greece.

Abd El Halim, A.O., Haas, R.C., Abd El Nabi, R.M., amd Abd El Aleem, A., 1996 "Effect of Highway Geometry and Construction Equipment on the Problem of reflection Cracks", Proceedings of the Third International Conference, Reflection Cracking in Pavements, Maastrichts, The Netherlands.

Thomas D. Gillespie, Steven M. Karamihas, David Cebon, Michael W. Sayers, Mohammad Asghar Nasim, Will Hansen, and Nadeem Ehsan, 1992 "Effects of Heavy Vehicle Characteristics on Pavement Response And Performance" Final Report Project 1 -25(1), UMTR1, The University of Michigan.

Chang, T., 2001. Effect of Vehicles Suspension on Highway Horizontal Curve Design. Journal of Transportation Engineering, Vol. 127, No. 1.

Christison, J. T., K. O. Anderson, 1978, "In Situ Measurements of Strains and Deflections in a FullDepth Asphaltic Concrete Pavement" Proceeding-Association of Asphalt Pavement Technologies 47(Minneapolis, Minn): pp.398-433.

Chatti, K., Kim, H.B., K. K. Yun, (1996). "Field Investigation into Effects of Vehicle Speed and Tire Pressure on Asphalt Concrete Pavement Strains" TRB. TRR 1539: pp. 66-71.

Mikhail, M. Y. and M. S. Mamlouk (1997). "Effects of Pavements-Vehicle Interaction on Pavement Response" TRB TRR 1570: pp. 78-88.

Pereira, P. A., J. C. Pais, (1999). "Modeling the Effect of Truck Speed on Permanent Deformation of Asphalt Concrete Mixes" Transportation Research Board.

Gonah, N. 2009. Relationship between Traffic Flow Characteristics and Pavement Condition on Roads in Egypt. Master Thesis, Civil \& Environmental Engineering Department, Al Azhar University, Cairo, Egypt. 